УДК 930.85

\title{
ВОСПРИЯТИЕ ПРОШЛОГО КАК КРИТЕРИЙ КУЛЬТУРНОГО РАЗНООБРАЗИЯ: ФЕНОМЕН РАSТ-ТИПОЛОГИИ
}

\author{
() 2020 М.Л. Шуб \\ Челябинский государственный институт культуры \\ Статья поступила в редакцию 28.10.2020
}

\begin{abstract}
Статья посвящена осмыслению возможностей прошлого как критерия культурного многообразия, то есть как основания выделения различных социокультурных типов. Автором обосновывается идея о том, что специфика восприятия прошлого в рамках той или иной культуры может продемонстрировать не только ее темпоральную ориентированность, но и ценностно-нормативные, идеологические, этические установки, доминирующие поведенческие модели и пр. На основании различных аспектов сложившегося образа прошлого можно выделять и различные типы культуры. В качестве таких оснований могут выступать: аксиологический статус прошлого (ретро-ориентированный, актуально-ориентированный, футуро-ориентированный и смешанные типы); эмоциональный вектор оценки прошлого (позитивный, негативный, сбалансированный типы); стратегии взаимодействия с прошлым (типы конструктивного и деструктивного взаимодействия), представления о динамической структуре прошлого (типы линейной и циклической pastтемпоральности); характер интегрированности прошлого в культуру (типы традиционной и искусственной преемственности); источник эталонной модели прошлого (типы религиозного, интеллектуального и художественного эталона) и др.

Ключевые слова: прошлое, восприятие прошлого, образ прошлого, типология культуры, past-типология.
\end{abstract}

DOI: $10.37313 / 2658-4816-2020-2-4-66-71$

Ключевые положения исследования осуществлены в рамках программы грантов

Президента Российской Федерации для государственной поддержки ведущих молодых российских ученых - докторов наук (Конкурс МД-2020),

проект «Культура памяти индустриальных городов российской провинции: мемориальные стратегии региональной идентичности».

\section{Введение. Прошлое как основание типологии культуры}

Смысл изучения историко-культурной проблематики в конечном итоге сводится к одному - к стремлению уловить определенные закономерности развития общества, выделить механизмы, лежащие в основе социокультурных процессов, увидеть уникальное и повторяемое в культуре и на этой основе - понять и объяснить современность и, насколько это возможно, хотя бы

Шуб Мария Львовна, доктор культурологии, доцент, заведующая кафедрой культурологии и социологии.E-mail: shubka_83@mail.ru гипотетически очертить контуры будущего. Типологизация как культурологический метод также способствует решению данной задачи, поскольку позволяет структурировать огромный массив историко-культурной эмпирики, соотнести его с различными смысловыми основаниями и, самое главное - встроить актуальность в пространство мировой культуры, определив ее место в пространстве истории.

Как известно, существует огромное множество критериев, позволяющих выделить тот или иной тип культуры - от диахронного до религиозного, от отношения к новациям 
- до доминирующего типа коммуникации.

В данной статье в качестве критерия предлагается рассмотреть критерий времени, а точнее - прошлого, а еще точнее - восприятия прошлого.

Отличительной чертой времени (точнее, восприятия времени) как типологизирующей категории является то, что оно (в отличие, скажем, от экономического уклада или форм хранения информации) относится не к внешним, экстериорным параметрам культуры, а составляет ее внутреннюю, интериорную среду, являясь одной из важнейших культурных универсалий и составляющих картины мира. А.Я. Гуревич писал по этому поводу: «Мало найдется других показателей культуры, которые в такой же степени характеризовали бы ее сущность, как понимание времени. В нем воплощается, с ним связано мироощущение эпохи, поведение людей, их сознание, ритм жизни, отношение к вещам. Достаточно сопоставить циклическое восприятие времени, доминировавшее у народов древнего Востока и в Античности, с финалистской концепцией движения мира от сотворения его к концу, к слиянию времени с вечностью в Средние века, для того чтобы стало ясным коренное различие в жизненной ориентации культуры древности и культуры средневекового христианства» ${ }^{1}$.

\section{Феномен past-типологии}

Ученые различных отраслей знания (историки, культурологи, антропологи, социологи) уделяли большое внимание феномену времени как основанию дифференциации культур. Достаточно назвать Ф. Артога 2 , Я. Ассмана ${ }^{3}$, М.С. Кагана ${ }^{4}$, Ж. Ле Гоффа ${ }^{5}$, К. Леви-Строса ${ }^{6}$, М. Мид ${ }^{7}$ и др. Не все исследователи стремились к построению именно типологических конструкций в строгом смысле этого слова, однако все они были ориентированы на демонстрацию специфики различных социокультурных типов по признаку «отношение ко времени».

Мы также попытаемся интерпретировать историко-культурную специфику восприятия времени как важный культурно-интегративный и культурно-дифференцирующий маркер. Кроме того, нам представляется перспективным подобный ракурс рассмотрения не только времени как такового, но и его отдельных модусов, в частности прошлого. На этом основании мы разработали авторскую past-типологию культуры, базирующуюся на целом ряде критериев.

1. Аксиологический статус прошлого (в данном случае имеется в виду общий ценностный вектор восприятия прошлого - его аксиологизация либо деаксиологизация и, соответственно, аксиологизация иных модусов времени):

- ретро-ориентированный тип: культура, ориентированная в своем развитии на прошлое как источник ценностей, проверенных истин, эталонных моделей поведения, как на «золотой век» - в историко-культурной призме данному типу соответствуют традиционные культуры (архаика, культуры цивилизаций Древнего Востока, Античности);

- актуально-ориентированный тип: культура, темпоральным основанием которой является настоящее (культура итальянского Ренессанса);

- футуро-ориентированный тип - культура, доминантным модусом времени которой выступает будущее, а наиболее значимыми ценностями, воплощение которых, как правило, связано с ближайшей перспективой, - развитие, прогресс, новационность и т.п. (в «чистом» виде такой тип не встречается, однако к нему можно отнести модель культуры, которая выстраивалась в среде европейских интеллектуалов - ученых, философов, общественных деятелей XVII и XVIII веков);

- смешанный тип: культура с латентной или синтетической темпоральной доминантой, когда преобладающий модус времени либо не проявлен, либо в рамках одной культуры сосуществуют сразу несколько аксиологизированных модусов (соответствует индустриальному и постиндустриальному этапам развития культуры, наиболее ярко 
проявлен в условиях современной социокультурной ситуации).

2. Эмоциональный вектор восприятия прошлого (общий оценочный вектор отношения к прошлому):

- позитивный тип: высокий ценностный статус прошлого, восприятие его либо в формате «золотого века» (архаика, греческая Античность), либо как значимой темпоральной среды, источника ценностей, опыта, наследия и т.п. (эпоха итальянского Ренессанса);

- негативный тип: критическое отношение к прошлому, как «обузе», «грузу» на теле культуры, препятствию для общественного развития, эпохе заблуждений и интеллектуальной неразвитости (в «чистом» виде не встречается, фиксируется лишь в локальных социокультурных формах - социальное движение презентизма в Древнем Риме, социально-философское движение Просвещения, секта «Настоящее» в Италии XVII века, движение модернизма в начале XX века и др.);

- сбалансированный тип: наличие в рамках одной культуры полярных позиций (негативной и позитивной) в отношении прошлого (европейская культура Нового времени) либо «эксплуатация» преференций, дающихся прошлым, осознание его культуросозидающей роли параллельно с аксиологизацией иных модусов времени (культура Средних веков, современная культура).

3. Доминирующие стратегии взаимодействия с прошлым (в основном коррелируются с предыдущим критерием, т.е. с эмоциональным вектором восприятия прошлого):

3.1. конструктивные стратегии: основаны на созидательном взаимодействии с прошлым, итогом которого выступает использование его потенциала для решения актуальных проблем, развития художественных форм, социокультурной рефлексии и пр. К некоторым конкретным примерам такого рода стратегий можно отнести:

- «ритуальное воспроизведение», в ходе которого прошлое (люди и события, его наполняющие) реинкарнируется в пространстве актуальности в акте обрядового повторения, а в настоящем воспроизводятся (иногда и на иррациональной основе) ценности, нормы, модели поведения, объяснительные схемы, имеющие свои архетипические прототипы в прошлом (хотя истоки данной стратегии лежат в недрах архаической культуры, ее примеры встречаются во всех историко-культурных типах, в том числе и в современном);

- «выигранный агон», подразумевающий состязательный характер взаимодействия с прошлым по принцу «кто - кого», стремление превзойти ученость и мастерство древних, опираясь тем не менее на опыт предшествующих поколений (в наиболее «чистом» виде такая стратегия встречалась в культуре итальянского Возрождения);

- «прагматичное почитание», в основе которого лежит уважительное отношение к прошлому как ресурсу решения конкретных, утилитарных вопросов - определение права собственности, обоснование древности рода, построение национальной мифологии и пр. (такого рода стратегии также широко представлены на всех этапах развития мировой и европейской в том числе культуры);

- «побег от настоящего», основанный, как правило, на ностальгических, меланхолических формах восприятия прошлого, на его идеализации и стремлении укрыться в его «анналах» от тяжести актуальных проблем, от чувства неприятия действительности и пр. (наиболее яркий пример распространения такой стратегии - европейская культура XIX - начала XX века);

- «игровая цитата», основанная на почтительном, но ироничном восприятии прошлого, заимствовании наследия прошлых эпох (интеллектуального, художественного) и его игровой деконструкции, комбинации новых культурных форм путем цитирования и перекомбинирования фрагментов прошлой реальности (такая стратегия зароди- 
лась и была наиболее востребованной в пространстве постмодернистской парадигмы во второй половине прошлого века);

3.2. деструктивные стратегии: основаны на разрушительных формах взаимодействия с прошлым, при которых деструкция может распространяться как на само прошлое, так и на современную культуру, такую стратегию применяющую:

- «тотальное отрицание», в основе которого лежит идея системного (интеллектуального, нравственного, художественного и др.) превосходства настоящего над прошлым, стремление вытеснить его «следы» (методы познания, интеллектуальные практики, мировоззренческие установки, идеалы и пр.) из пространства актуальной культуры как признаки архаики, устаревания и деградации, противопоставив им контрапунктные идеи развития, прогресса, новационности, модернизации (наиболее ярко данная стратегия проявилась в интеллектуальной, научно-философской среде XVII - XVIII вв. и в эстетико-художественном движении модернизма);

- «руинирование» - физическая ликвидация прошлого, его символов и «следов», как правило, в контексте революционной борьбы или смены политических, религиозных, идеологических режимов (разрушение памятников римским императорам христианами в эпоху поздней римской империи, сожжение языческих книг в Средние века, уничтожение монастырских крипт с захоронениями французских королей во время Французской революции);

- «изгнание из памяти», подразумевающее организацию осознанного, целенаправленного забвения фрагментов прошлого, реализацию «политики забывания»: изъятие книг, запрет на упоминание исторических фактов или персоналий, выключение из коммеморативных практик и пр. (данная стратегия носит универсальноисторический характер и использовалась на всем протяжении развития культуры);

- «слепое подражание», основанное на диктате традиции и канона, на механи- ческом копировании образцов прошлого (проявляется в практике средневекового богословского писания, в тотальной, внетворческой ориентации на классические, канонические художественные образцы в эпоху Маньеризма второй половины XVI века, в эстетической доктрине академизма - вторая половина XVIII - вторая половина XIX века);

- «манипуляция» - использование разного рода манипулятивных форм обращения с прошлым с целью реализации властных интересов («властью» в данном контексте могут выступать не только политические элиты, но и влиятельные экономические круги, и церковь) - фальсификация, искажение исторических фактов, конструирование исторических мифов и пр.

Безусловно, спектр возможных стратегий взаимодействия с прошлым не исчерпывается обозначенными выше. Мы привели лишь наиболее общие и распространенные из них.

4. Динамическая модель прошлого:

- циклический тип: основан на идее темпорального круговорота и на образе возвращаемого прошлого (характерен для архаичной, античной и отчасти средневековой, ренессансной культур);

- линейный тип: подразумевает осмысление прошлого как необратимой, безвозвратно ушедшей темпоральной реальности, расположенной на оси временных координат перед настоящим (европейская культура Нового и Новейшего времени).

5. Социально-перцептивная модель прошлого (специфика разделяемости образа/образов прошлого):

- универсально-тотальный тип: основан на существовании единого образа прошлого, разделяемого в той или иной степени всеми социальными группами (характерен, например, для архаической и античной культур);

- разрозненно-дискретный тип: подразумевает существование конгломерата образов прошлого в рамках единого культурного пространства, во-первых, ориенти- 
рованных на различные социальные группы (в зависимости от их сословного статуса, материального положения, интеллектуального развития, профессиональной ориентации и пр.), во-вторых, формирующихся вокруг доминантного (официального) образа, в-третьих, как правило, в большей или меньшей степени конвергирующих друг с другом (народные представления разделяются интеллектуальной элитой, официальные религиозные представления о прошлом насаждаются в крестьянской среде и пр.). Различные образы прошлого могут либо относительно гармонично сосуществовать в рамках единой темпоральной картины мира (как в Средневековье), либо бытовать в формате столкновения и оппозиционности (как в культуре Нового времени).

6. Характер интегрированности прошлого в культуру (специфика и глубина взаимосвязи прошлого и настоящего):

- тип традиционной преемственности (прошлое глубоко интегрировано в пространство культуры благодаря естественному функционированию механизмов преемственности, таких как традиция, обычай, коммуникативная память и др., постоянно воспроизводится в формате обрядовой когерентности);

- тип искусственной преемственности (прошлое существует как автономный модус времени, искусственно интегрируемый в пространство настоящего через институализированные, целенаправленные и управляемые формы - наследие, культурная память, «места памяти», «изобретенные традиции», коммеморативные практики и пр.).

7. Источник эталонной модели прошлого (институция, социальная или политическая сила, являющаяся источником формирования и трансляции «официального», доминантного образа или нескольких образов прошлого):

- тип религиозного эталона (источником формирования образа прошлого выступают религиозные представления, воплощенные в ритуально-обрядовой деятельности ша- манов или доктринно-догматических установках института Церкви - характерен для архаической, древнегреческой и средневековой культур, в латентном виде присутствует во всех историко-культурных типах);

- тип интеллектуального эталона (образ прошлого формируется на основе его интеллектуальной концептуализации в трудах философов, ученых, общественных деятелей и пр. - характерен для древнеримской, ренессансной культуры, отчасти для европейской культуры Нового и Новейшего времени);

- тип художественного эталона (в данном случае можно говорить не столько о формировании, сколько о воплощении, трансляции, популяризации, закреплении образа прошлого в пространстве художественного творчества).

8. Доминантный признак образа прошлого (наиболее специфическая черта, присущая образу прошлого в рамках той или иной культуры, наиболее репрезентативная тенденция, характеризующая его восприятие):

- фантомный тип;

- фрактальный тип;

- полифонический тип;

- реинкарнированный тип;

- контрапунктный тип;

- рандомный тип.

\section{Заключение}

Безусловно, любая типология охватывает лишь общие черты феномена, намечает лишь базовые тенденции, происходящие в обществе. Ее результат - своего рода веберовский идеальный тип, абстрактная конструкция, выполняющая функции инструмента познания. Любая типология не может охватить всего динамического разнообразия явлений, присущих той или иной культуре. Более того, границы между отдельными типами представляются более чем условными и размытыми. Типологию можно сравнить с карандашным рисунком, с контуром, наносимым художником на полотно, чтобы уловить границы 
трехмерной реальности в плоском, двухмерном изображении. Однако при всех ограничениях типология дает обширные познавательные возможности, позволяет упорядочить, структурировать историкокультурное многообразие, локализовав его в обобщенные культурные формы, увидеть закономерности социокультурного развития, его типичные и уникальные проявления.

Эти же задачи выполняет и pastтипология. Прошлое, выступающее ее критериальным основанием, является призмой, сквозь которую преломляется весь историко-культурный процесс в целом и развитие отдельных культур в частности. На основании анализа образа прошлого, сложившегося в той или иной культуре, можно не только нарисовать ее темпоральный «портрет», но и составить комплексное, системное представление о ее специфике: идеологических основаниях, формах и характере социального взаимодействия, ценностных установках, нравственных ори- ентирах, нормированных и табуированных моделях поведения, векторах целеполагания и проспективных ориентирах, механизмах преемственности и др. Проще говоря, чтобы понять культуру, надо понять, что ее носители думали о прошлом.

\section{ПРИМЕЧАНИЯ}

${ }^{1}$ Гуревич А.Я. Категории Средневековой культуры. М.: Искусство, 1984. 350 с.

${ }^{2}$ Артог Ф. Порядок времени, режимы историчности // Неприкосновенный запас. 2008. № 3 (59). С. 17-29.

${ }^{3}$ Ассман Я. Культурная память: Письмо, память о прошлом и политическая идентичность в высоких культурах древности. М.: Языки славянской культуры, 2004. 368 с.

${ }^{4}$ Каган М.С. Пространство и время как культурологические категории // Вестник СПбГУ. 1993. Сер. 6. Вып. 4. С. 30-40.

5 Ле Гофф Ж. История и память. М.: Рос. полит. энцикл. (РОССПЭН), 2013. 303 с.

${ }^{6}$ Леви-Строс К. Первобытное мышление. М.: Республика, 1994.384 с.

${ }^{7}$ Мид М. Культура и мир детства. М.: Наука, 1988. 429 c.

\title{
PERCEPTION OF THE PAST AS A CRITERION FOR CULTURAL DIVERSITY: THE PHENOMENON OF PAST-TYPOLOGY
}

\author{
(C) 2020 M.L. Shub
}

\begin{abstract}
Chelyabinsk State Institute of Culture
The article is devoted to comprehending the possibilities of the past as a criterion of cultural diversity, that is, as a basis for identifying various sociocultural types. The author substantiates the idea that the specificity of the perception of the past within the framework of a particular culture can demonstrate not only its temporal orientation, but also valuenormative, ideological, ethical attitudes, dominant behavioral models, etc. On the basis of various aspects of the existing image of the past, one can distinguish and different types of culture. Such grounds can be: the axiological status of the past (retro-oriented, actualoriented, future-oriented and mixed types); emotional vector of assessing the past (positive, negative, balanced types); strategies for interacting with the past (types of constructive and destructive interaction), ideas about the dynamic structure of the past (types of linear and cyclical past-temporality); the nature of the integration of the past into culture (types of traditional and artificial continuity); source of the reference model of the past (types of religious, intellectual and artistic standards), etc.

Keywords: past, perception of the past, image of the past, typology of culture, past typology.

DOI: $10.37313 / 2658-4816-2020-2-4-66-71$
\end{abstract}

Maria Shub, Doctor of Culturology, Associate

Professor, Head of the Department of Cultural Studies

and Sociology.E-mail: shubka_83@mail.ru 